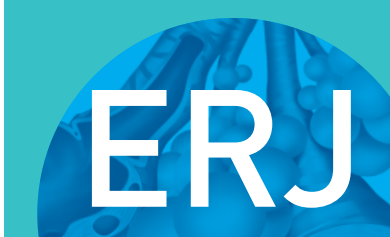

open research
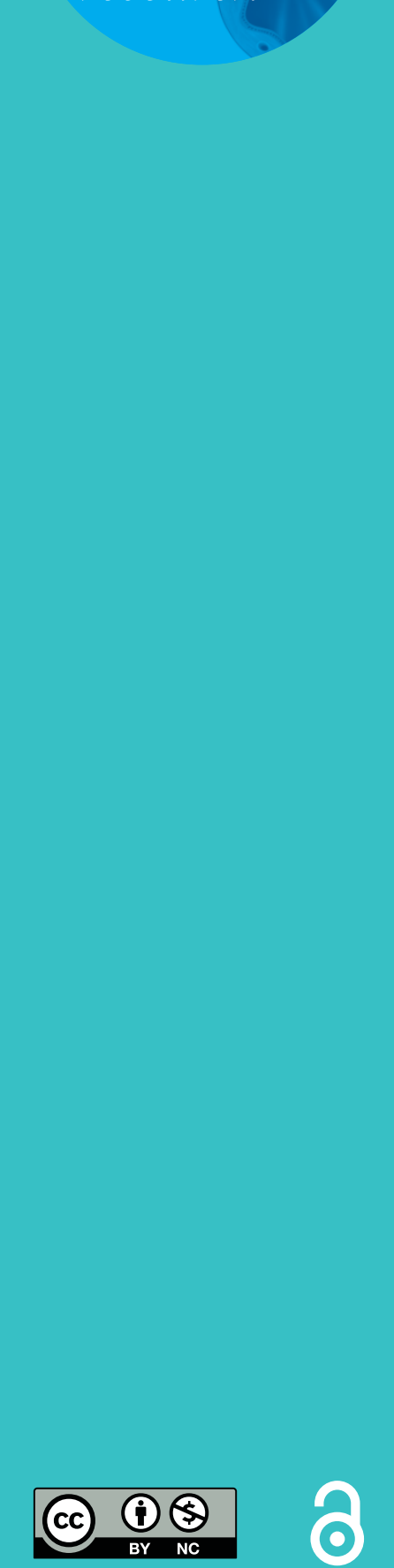

\section{Biometric monitoring in silicosis to detect early disease and monitor lung injury: not quite there}

\section{From the authors:}

We would like to thank D. Weiler Ravell and H. Bishara for their comments about our recent paper [1], and take this opportunity to reply. While their observation that $63.2 \%$ of our cohort already had silicosis negates the definition of "early diagnosis" is correct, $36.8 \%$ of the exposed workers had neither a previous diagnosis of silicosis nor clinical symptoms, and they were considered "healthy workers" and, as such, they are monitored by spirometry and chest radiographic findings once in 3 years. Our biomarker revealed that they had exposure-induced inflammation and a high load of hazardous dust in the airways, thus alerting for close monitoring and medical observation and, most importantly, precautionary measures at the workplace. In Israel, the manufacture of kitchen and bath countertops is based mainly on artificial stone that contains 93\% silica as natural quartz, and 3500 workers are currently involved in cutting and processing it. We estimate that there should be more than 1000 "healthy workers" exposed to artificial stone dust who already have inflammatory abnormalities and high load of dust in their airways. We claim that implementation of the preventive biomonitoring measures that we recommend are sensitive and that the early detection that they enable may lead to avoidance or slowing down of the disease process.

We cite two of our earlier works $[2,3]$ to support our claim that the neutrophil count is a robust biomarker to detect time-dependant occupational exposure to hazardous dust.

The first report was on firefighters that were on duty during the World Trade Center collapse: their neutrophil count was correlated to the time of working at "ground zero" [2]. In the second report, the neutrophil count was correlated to the years of exposure to airborne particles in the workplace of a cohort of welders [3].
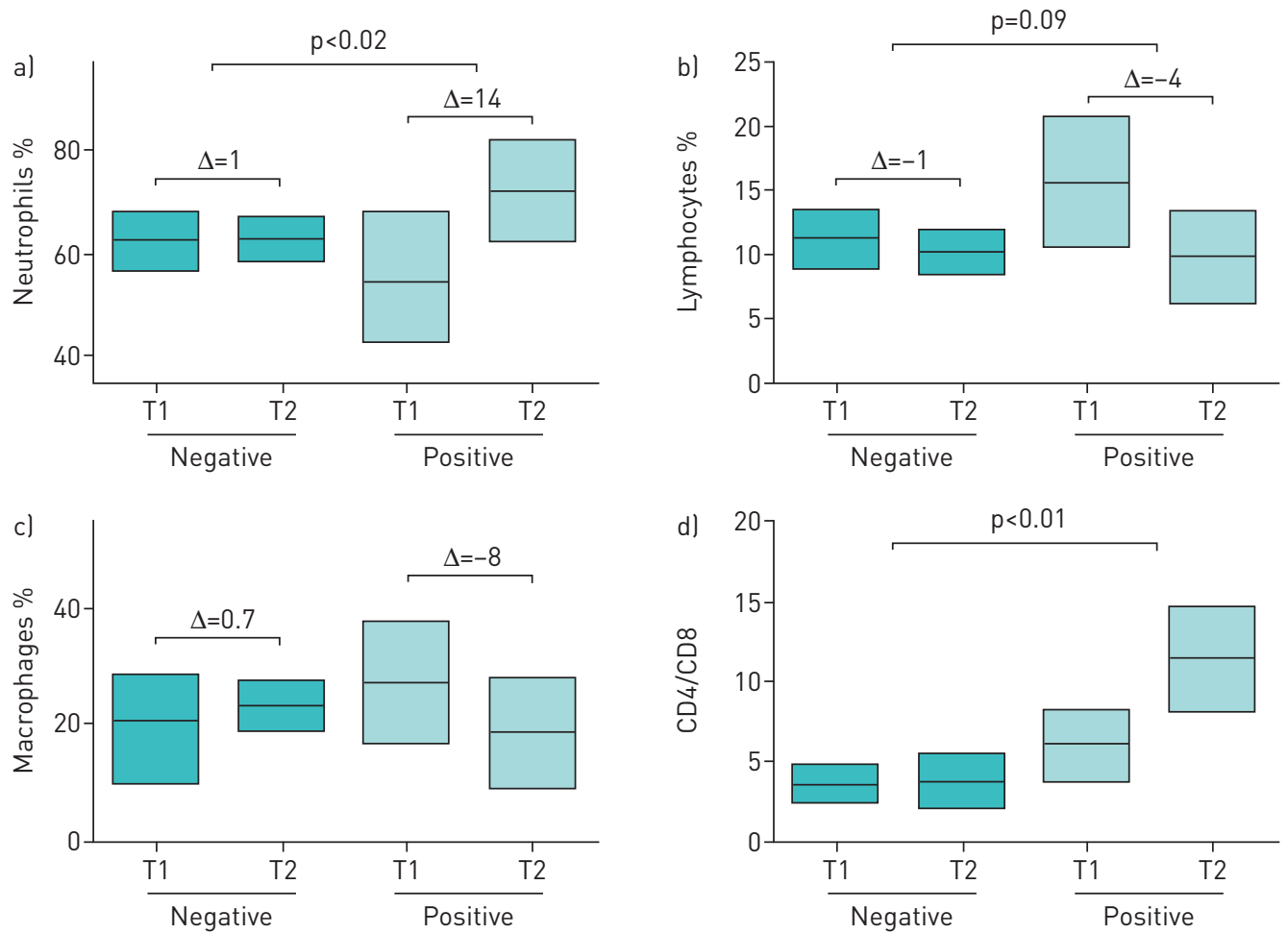

FIGURE 1 Differential cell counts in induced sputum in groups negative or positive for the beryllium lymphocyte proliferation test (which measures sensitisation to beryllium). Each bar shows the mean (internal line) and $95 \%$ confidence interval. T1: baseline; T2: 2 years of follow-up; $\Delta$ : change in mean. 
The point made by D. Weiler Ravell and H. Bishara regarding a “...follow-up over time with serial tests to detect a temporal relationship between increased levels of inflammatory biomarkers and the risk of silicosis..." is very well taken. We have just completed a 4-year prospective study on a group of dental technicians exposed to beryllium and hard metal alloys who were monitored by us for a period of 4 years. Induced sputum was performed at enrolment to the study and followed-up after 2 years. Neutrophil counts were found to be the main biomarker that significantly increased in correlation to sensitisation to beryllium (figure 1) over the years.

While D. Weiler Ravell and H. Bishara are correct in noting that we did not break down the definition of "past smoker", the variable of a past smoking history as well as age, sex and weight between the exposed population and the control group were considered and adjusted during the statistical evaluation.

We did not specify how our samples were collected at the workplace. The first author retrieved them from the surface of the cutting machines in plants that dealt exclusively with artificial stone. All the samples were contaminated with metals.

As for the number of patients in each group: the inclusion of the word "exposed" was an error: there were 116 study participants, of whom 68 were exposed to hazardous dust and 48 had not been exposed and served as controls.

Finally, we please note that we did not mention Caesarstone so much as once in our entire paper.

Noa Ophir and Elizabeth Fireman

Occupational Environmental Medicine Dept, Tel Aviv University-Sackler School of Medicine, Tel Aviv Medical Center, Tel Aviv, Israel.

Correspondence: Elizabeth Fireman, Occupational Environmental Medicine Dept, Tel Aviv University-Sackler School of Medicine, Tel Aviv Medical Center, 6 Weizman St, Tel Aviv 6423906, Israel.

E-mail: fireman@tlvmc.gov.il

Received: Aug 182016 | Accepted: Aug 312016

Conflict of interest: None declared.

@ERSpublications

Biomonitoring of artificial stone-exposed workers http://ow.ly/Ut4J304amUr

Copyright CERS 2016. This article is open access and distributed under the terms of the Creative Commons Attribution NonCommercial Licence 4.0.

\section{References}

1 Ophir N, Bar Shai A, Alkalay Y, et al. Artificial stone dust-induced functional and inflammatory abnormalities in exposed workers monitored quantitatively by biometrics. ERJ Open Res 2016; 2: 00086-2015.

2 Fireman EM, Lerman Y, Ganor E, et al. Induced sputum assessment in New York City firefighters exposed to World Trade Center dust. Environ Health Perspect 2004; 112: 1564-1569.

3 Fireman E, Lerman Y, Stark M, et al. Detection of occult lung impairment in welders by induced sputum particles and breath oxidation. Am J Indust Med 2008; 51: 503-511. 